\title{
Molecular Characterization of Heterotic Groups of Cotton through SSR Markers
}

\author{
H.G. Kencharaddi*, R.R. Hanchinal, S.S. Patil, S.M. Manjula, \\ Ravi Kulkarni, C.V. Usharani and C.D. Soregoan \\ Department of Genetic and Plant Breeding, University of Agricultural Sciences, \\ Dharwad - 580 005, Karnataka, India \\ *Corresponding author
}

\section{Keywords}

Cotton (Gossypium hirsutum L.), SSR Makers

Article Info

Accepted: 04 February 2018 Available Online: 10 March 2018

\section{A B S T R A C T}

Knowledge of genetic diversity and relationships among breeding materials has a significant impact on crop improvement. Association between parental divergence and progeny performance has not been well documented in cotton (Gossypium hirsutum L.). This study was conducted to estimate genetic diversity based on simple sequence repeat (SSR) markers among the selected elite cotton genotypes belong to different heterotic groups developed at ARS, Dharwad. A total of 81 alleles were detected from 24 SSR primers. Among these, 62 were polymorphic with an average of 70.29 per cent polymorphism. The number of alleles per SSR locus ranged from 1 to 13 with an average of 3.37. The per cent polymorphism was 0.00 to 100.00 per cent with an average 70.29. Primers viz., BNL 2920, BNL2882, BNL 1059, BNL3171, BNL3994, CIR246, CIR351, CIR070,CIR 100, CIR182, CIR200, CIR238,CIR034, CIR004, CIR373, CIR393, JESPR195 66, JESPR 29 JESPR 58 and NAU3485 exhibited the highest (more than 50\%) per cent polymorphism. The number of bands ranged from four (primers BNL 3418) to 91 (primers JESPR58) with an average of 20.40 bands per primer. In case of compact groups, lines DC-ANJ and DC095-7 revealed highest (0.91) similarity coefficient value followed by DC095-7 and DC 4-11 (0.74), DC-ANJ and DC095-7 (0.73). Among robust lines, DRAC 9565 and DR 2 recorded highest $(0.78)$ followed by DRL- 88 and DRAC -9565 (0.74). In case stay green groups, highest similarity coefficient value $(0.81)$ was observed between DSG-79-61-1 and DSG-3-5 line followed by DSG-102 and DSG-3-5 (0.79). Among the elite lines of high RGR, highest similarity was observed between DRGR-24178 and DRGR-257 (0.75) followed by DRGR-32-100 and DRGR-257 (0.71). All the parental lines showed diversity among themselves indicating that there is considerable amount of variation, which can be exploited through appropriate breeding programme.

\section{Introduction}

Breeding programmes depend on a high level of genetic diversity for achieving progress from selection. Broadening the genetic base of core breeding material requires the identification of diverse strains for hybridization with elite cultivars.

Numerous studies investigating the assessment of genetic diversity within breeding material have been reported in all crops. 
Morphological features are indicative of genotype but are represented by only a few loci because they are not large enough. Moreover, they can also be affected by environmental factors and cultural practices. In the past the ability to discriminate between varieties was heavily dependent on morphological traits. Lately, DNA markers have been employed as promising tools. DNA molecular markers are employed for genetic diversity estimation in place of morphological markers as number of morphological descriptors various in crops is in vogue for characterization purpose. Observed polymorphism is independent from effects caused due to environmental conditions and physiological stage of plant makes molecular markers a reliable tool for diversity studies.

DNA markers have also been used to define heterotic groups that can be used to exploit heterosis (hybrid vigour). The development of inbred lines for use in producing superior hybrids is a relatively time-consuming and expensive procedure. Unfortunately, it is not yet possible to predict the exact level of heterosis based on DNA marker data although there have been reports of assigning parental lines to the different heterotic groups. The potential use of smaller subsets of DNA marker data in combination with phenotypic data to select heterotic hybrids has also been proposed. Hence, present study was planned with the intention of exploitation of heterotic groups based on conventional and molecular (SSR) markers.

\section{Materials and Methods}

\section{Plant materials and molecular markers used in the study}

Five elite lines from each heterotic groups viz., compact, robust, stay green and high RGR. Were used for 24 sets of cotton micro satellite markers (SSR) linked to yield and yield component traits as mentioned in Table 1 and 2 , respectively.

\section{SSR molecular marker analysis}

Leaf tissue of each parent was harvested and total genomic DNA was extracted from young leaves using the hexadecyl-trimethyl ammonium bromide (CTAB) method described by Saghai-Maroof et al., (1984). SSR assays were performed using 24 oligonucleotide primers from Sigma Aldrich Chemicals Pvt. Ltd., Co. Amplification reactions were carried out in $20 \mathrm{~mL}$ volumes containing $2.0 \mathrm{~mL} 10 \times$ assay buffer, $2.0 \mathrm{~mL}$ dNTP mix (2.5 mM each), $0.5 \mathrm{~mL}$ forward primer $(5 \mathrm{pM} / \mathrm{mL}), \quad 0.5 \mathrm{ml}$ Reverse (5 $\mathrm{pM} / \mathrm{mL}), \quad 0.5 \mathrm{~mL}$ Taq DNA polymerase (3U/mL), $2.0 \mathrm{~mL}$ Template DNA $(15 \mathrm{ng} / \mathrm{mL})$ and $7.5 \mathrm{~mL}$ Sterile double distill water. The amplification programmed for $5 \mathrm{~min}$ at $94^{\circ} \mathrm{C}$ Denaturation (initial) of genomic DNA by one cycle followed by 25 cycles of $1 \mathrm{~min}$ at $94^{\circ} \mathrm{C}$, $1 \mathrm{~min}$ at $48 \pm 5^{\circ} \mathrm{C}$ and $1 \mathrm{~min}$ at $72^{\circ} \mathrm{C}$. This was followed by a final extension at $72{ }^{\circ} \mathrm{C}$ for 5 min. Amplification products were analysed by Non-Denaturing gel electrophoresis (PAGE) and viewed by silver staining.

\section{Scoring the amplified fragments}

The amplification of DNA profiles for all the primers were compared with each other and the bands of DNA at each amplification level of every primer were scored as present (1) or absent (0) thus generating the 0,1 matrix.

Total No. of polymorphic bands Per cent polymorphism $(\%)=------------\times 100$

Total No. of bands generated by 24 primers

\section{Analysis of SSR profiles}

Pair similarity coefficients were calculated for all pairwise combinations of the parental lines according to the method developed by Nei and 
Li (1979): $S i j=2 N i j /(N i+N j)$, where $S i j$ is the similarity between parents $i$ and $j$; Nij is the number of bands present in both parents; $\mathrm{Ni}$ is the number of bands present only in parent I; $N j$ is the number of bands present only in parent $j$. GD (genetic distance) was calculated as $\mathrm{GD}=1-\mathrm{Sij}$.

The similarity matrix from SSR markers, which were computed using NTSYS-PC version 2.1 (Rohlf, 2001) were used to construct dendrograms based on UPGMA (the unweighted pair- group method with arithmetic means). Using the same NTSYS software, a cophenetic value matrix was calculated to test the goodness of fit for the cluster analysis to the original distance matrix.

\section{Results and Discussion}

The use of molecular markers will help to study the genetic relationship among cotton genotypes. DNA based molecular markers acted as a versatile tool to study variability and diversity in different plant species. The search for superior hybrid parents in cotton breeding programmes is commonly based on the estimation of the general combining ability (gca) and specific combining ability (sca) in lines.

However, the application of this procedure is relatively an expensive and time consuming process. The development of DNA based markers represent an alternative procedure for the identification of promising parental lines for superior performances of hybrids. The microsatellite (SSR's) markers have been widely used for the estimation of variation among closely related individuals due to its multiallelic nature and high polymorphism. Molecular markers based on polymorphism of DNA are especially useful for this purpose because they are not affected by environment (Tatineni et al., 1996 and Saghai- Maroof et al., 1984). Several examples of the application of molecular markers to estimate genetic distances have been reported in maize (Smith et al., 1990) and rice (Zhang et al., 1995). Thus, molecular markers like SSR's (microsatellite) could be used for germplasm classification and clustering to derive valuable information. A total of 81 alleles were detected from 24 SSR primers. Among these, 62 were polymorphic with an average of 70.29 per cent polymorphism.

The number of alleles per SSR locus ranged from 1 to 13 (Table 3) with an average of 3.37. The per cent polymorphism was 0.00 to 100.00 per cent with an average 70.29. Primers viz., BNL 2920, BNL2882, BNL 1059, BNL3171, BNL3994, CIR246, CIR351, CIR070,CIR 100, CIR182, CIR200, CIR238,CIR034, CIR004, CIR373, CIR393, JESPR195 66, JESPR 29 JESPR 58 and NAU3485 exhibited the highest (more than $50 \%)$ per cent polymorphism. The number of bands ranged from four (primers BNL 3418) to 91 (primers JESPR58) with an average of 20.40 bands per primer. In case of compact groups, lines DC-ANJ and DC095-7 showed the highest (0.91) similarity coefficient value followed by DC095-7 and DC 4-11 (0.74), DC-ANJ and DC095-7 (0.73). Among robust lines, DRAC 9565 and DR 2 recorded highest (0.78) followed by DRL-88 and DRAC -9565 (0.74).

In case stay green elite lines highest similarity coefficient value $(0.81)$ was observed between DSG-79-61-1 and DSG-3-5 followed by DSG102 and DSG-3-5 (0.79) (Table 4). Among the elite lines of high RGR, highest similarity was observed between DRGR-24-178 and DRGR257 (0.75) followed by DRGR-32-100 and DRGR-257 (0.71). All the parental lines showed diversity among themselves indicating that there is considerable amount of variation, which can be exploited through appropriate breeding programme (Fig. 1). 
Table.1 Experimental material used for molecular diversity analysis using 24 SSR Markers

\begin{tabular}{|c|}
\hline Sl. No. \\
\hline 1 \\
\hline 2 \\
\hline 3 \\
\hline 4 \\
\hline 5 \\
\hline 6 \\
\hline 7 \\
\hline 8 \\
\hline 9 \\
\hline 10 \\
\hline 11 \\
\hline 12 \\
\hline 13 \\
\hline 14 \\
\hline 15 \\
\hline 16 \\
\hline 17 \\
\hline 18 \\
\hline 19 \\
\hline 20 \\
\hline
\end{tabular}

\begin{tabular}{|c|c|}
\hline Heterotic Groups & Genotype \\
\hline Robust & DRBM \\
\hline Robust & DR2 \\
\hline Robust & DRAC 9565 \\
\hline Robust & DSMR-10 \\
\hline Robust & DRL-88 \\
\hline Stay green & GSG 16 \\
\hline Stay green & GSG 100 \\
\hline Stay green & DSG-3-5 \\
\hline Stay green & DSG 79-61-1 \\
\hline Stay green & DSG-102 \\
\hline High RGR & DRCR-041 \\
\hline High RGR & DRGR-257 \\
\hline High RGR & DRGR-24-178 \\
\hline High RGR & DRGR-32-100 \\
\hline High RGR & DRGR-308 \\
\hline Compact & DC 95-118 \\
\hline Compact & DC 4-11 \\
\hline Compact & DC-58-7 \\
\hline Compact & DC-095-7 \\
\hline Compact & DC-ANJ \\
\hline
\end{tabular}

Table.3 Analysis of SSR patterns generated using 24 primers pairs in elite genotypes

\begin{tabular}{|c|c|c|c|c|}
\hline SI. No. & Primers & No. of polymorphic alleles & No. of Alleles & Percent Polymorphism \\
\hline 1 & BNL2920 & 4 & 4 & 100 \\
\hline 2 & BNL2882 & 3 & 5 & 80 \\
\hline 3 & BNL1059 & 3 & 4 & 75 \\
\hline 4 & BNL3418 & 0 & 1 & 0 \\
\hline 5 & BNL3259 & 0 & 1 & 0 \\
\hline 6 & BNL1440 & 0 & 1 & 0 \\
\hline 7 & BNL3171 & 2 & 3 & 66 \\
\hline 8 & BNL3408 & 2 & 5 & 40 \\
\hline 9 & BNL3994 & 1 & 1 & 100 \\
\hline 10 & CIR246 & 2 & 2 & 100 \\
\hline 11 & CIR381 & 2 & 3 & 66 \\
\hline 12 & CIR070 & 2 & 3 & 66 \\
\hline 13 & CIR100 & 2 & 2 & 100 \\
\hline 14 & CIR182 & 2 & 3 & 66 \\
\hline 15 & CIR238 & 2 & 2 & 100 \\
\hline 16 & CIR034 & 1 & 1 & 100 \\
\hline 17 & CIR004 & 1 & 1 & 100 \\
\hline 18 & CIR373 & 1 & 1 & 100 \\
\hline 19 & CIR393 & 0 & 1 & 0 \\
\hline 20 & CIR030 & 4 & 5 & 80 \\
\hline 21 & JESPR195 & 4 & 6 & 66 \\
\hline 22 & JESPR29 & 3 & 3 & 100 \\
\hline 23 & JESPR58 & 12 & 13 & 92 \\
\hline \multirow[t]{2}{*}{24} & NAU3485 & 9 & 10 & 90 \\
\hline & Total & 62 & 81 & 70.29 \\
\hline
\end{tabular}


Table.2 List of SSR primers used for diversity analysis

\begin{tabular}{|c|c|c|c|}
\hline Sl. No. & Marker Name & Forward Primer (5’-3’) & Reverse Primer ( $\left.3^{\prime}-5^{\prime}\right)$ \\
\hline 1 & BNL2920 & TTCTTGCATTGAATAATACTGGC & СTTAАTTCTAАAАATCAATAAATTTAGCC \\
\hline 2 & BNL2882 & CAACCTTTGGTAATCTTCTTTCG & CGCTAACGCATTTGACATCT \\
\hline 3 & BNL1059 & CCTTCTCTGACACTCTGCCC & TGTATTCTCTTCTTTTCСТTATACTTTT \\
\hline 4 & BNL3418 & GATGCCAGTGAGATCCCAAT & TCAGTGGAGATGGTCATATGC \\
\hline 5 & BNL3259 & TTTTGAAATTCCAGCGAAGG & GTCAATACCTGCTTCTCCACG \\
\hline 6 & BNL1440 & CCGAAATATACTTGTCATCTAAACG & CCCCCGGACTAATTTTTCAA \\
\hline 7 & BNL3171 & GAAAAATTGAGGAAGGACATACG & GGCCACAACCGAATTTACTG \\
\hline 8 & BNL3408 & ATCCAAACCATTGCACCACT & GTGTACGTTGAGAAGTCATCTGC \\
\hline 9 & BNL3994 & TTGAGGGCATCCAAATCCAT & CCTCCACCATACACGTGCTA \\
\hline 10 & CIR246 & TTAGGGTTTAGTTGAATGG & ATGAACACACGCACG \\
\hline 11 & CIR381 & TTTCCATCCTTTTGTGA & AAGGAGAAGAACAAGCAA \\
\hline 12 & CIR070 & AACCACCAACCATTCA & TGGGACTCGGTCATC \\
\hline 13 & CIR100 & GAGAGGCGATGCTAAA & GGGATACAAATGGAGAAA \\
\hline & & & Contd... \\
\hline $\begin{array}{l}\text { Sl. } \\
\text { No. }\end{array}$ & Marker Name & Forward Primer (5’-3’) & Reverse Primer $\left(3^{\prime}-5^{\prime}\right)$ \\
\hline 14 & CIR182 & CTTCATCATAGTAGCGAGTT & GAATCAAGCAGAGGATTT \\
\hline 15 & CIR238 & TCAACTCACCGATTACAC & TCTTCATTCGGGCTT \\
\hline 16 & CIR034 & TTGAACCAAGAATGGAA & TGTCACGCCATATACACT \\
\hline 17 & CIR004 & ACAAATCCCATTCACG & GGTTTGCTAGTGTCCTTT \\
\hline 18 & CIR373 & ACCATTGACTTCCCTGT & CCCTCTTGGTGTTATGTC \\
\hline 19 & CIR393 & GACCACACAGACAGACAA & TCCACAACCAAACTAACA \\
\hline 20 & CIR030 & CAATATCTCACTTGGACCT & TGCTACACATCATAGTTGG \\
\hline 21 & JESPR195 & GATCTGGACTAAACTAGTTGATGTG & GCCAATAATGGATGAAGGTTAC \\
\hline 22 & JESPR29 & CACCGTTTCCAAGTAAGATT & GGTTAATCTTAGTTGAGGTC \\
\hline 23 & JESPR58 & CCGCCCTTCTCTTGCTTAGATCTGG & GGAGCCAATTGAGAAGTGAATCCAA \\
\hline 24 & NAU3485 & GTTCAAAGTCGGGTTATTGG & AGTGCAACGGCTTAGGATAC \\
\hline
\end{tabular}


Table.4 Genetic similarity coefficients between the elite lines of heterotic groups

\begin{tabular}{|c|c|c|c|c|c|c|c|c|c|c|c|c|c|c|c|c|c|c|c|c|}
\hline Genotypes & DRBM & DR2 & $\begin{array}{c}\text { DRAC } \\
9565\end{array}$ & $\begin{array}{l}\text { DSMR- } \\
10\end{array}$ & $\begin{array}{c}\text { DRCR- } \\
\quad 8\end{array}$ & $\begin{array}{c}\text { GSG } \\
16\end{array}$ & $\begin{array}{c}\text { GSG } \\
100\end{array}$ & $\begin{array}{c}\text { DSG- } \\
\text { 3-5 }\end{array}$ & $\begin{array}{c}\text { DSG } \\
79- \\
61-1\end{array}$ & $\begin{array}{c}\text { DSG- } \\
102\end{array}$ & $\begin{array}{c}\text { DRCR- } \\
4\end{array}$ & $\begin{array}{c}\text { DRGR- } \\
257\end{array}$ & $\begin{array}{c}\text { DRGR- } \\
24-178\end{array}$ & $\begin{array}{l}\text { DRGR- } \\
\text { 32-100 }\end{array}$ & $\begin{array}{l}\text { DRGR- } \\
308\end{array}$ & $\begin{array}{l}\text { DC } \\
95- \\
118\end{array}$ & $\begin{array}{c}\text { DC } \\
4- \\
11\end{array}$ & $\begin{array}{c}\text { DC- } \\
58- \\
7\end{array}$ & $\begin{array}{c}\text { DC- } \\
095- \\
7\end{array}$ & $\begin{array}{l}\text { DC- } \\
\text { ANJ }\end{array}$ \\
\hline DRBM & 1.00 & & & & & & & & & & & & & & & & & & & \\
\hline DR2 & 0.71 & 1.00 & & & & & & & & & & & & & & & & & & \\
\hline $\begin{array}{l}\text { DRAC } \\
9565\end{array}$ & 0.74 & 0.78 & 1.00 & & & & & & & & & & & & & & & & & \\
\hline DSMR-10 & 0.58 & 0.61 & 0.61 & 1.00 & & & & & & & & & & & & & & & & \\
\hline DRCR-8 & 0.58 & 0.66 & 0.74 & 0.65 & 1.00 & & & & & & & & & & & & & & & \\
\hline GSG 16 & 0.59 & 0.55 & 0.60 & 0.64 & 0.66 & 1.00 & & & & & & & & & & & & & & \\
\hline GSG 100 & 0.68 & 0.49 & 0.64 & 0.55 & 0.58 & 0.74 & 1.00 & & & & & & & & & & & & & \\
\hline DSG-3-5 & 0.68 & 0.54 & 0.54 & 0.58 & 0.58 & 0.66 & 0.78 & 1.00 & & & & & & & & & & & & \\
\hline $\begin{array}{l}\text { DSG 79- } \\
61-1\end{array}$ & 0.69 & 0.63 & 0.58 & 0.59 & 0.56 & 0.73 & 0.64 & 0.81 & 1.00 & & & & & & & & & & & \\
\hline DSG-102 & 0.59 & 0.48 & 0.45 & 0.56 & 0.46 & 0.55 & 0.61 & 0.79 & 0.78 & 1.00 & & & & & & & & & & \\
\hline DRCR-4 & 0.55 & 0.46 & 0.46 & 0.60 & 0.55 & 0.69 & 0.70 & 0.63 & 0.56 & 0.66 & 1.00 & & & & & & & & & \\
\hline $\begin{array}{l}\text { DRGR- } \\
257\end{array}$ & 0.61 & 0.60 & 0.50 & 0.64 & 0.54 & 0.68 & 0.69 & 0.64 & 0.63 & 0.53 & 0.71 & 1.00 & & & & & & & & \\
\hline $\begin{array}{l}\text { DRGR-24- } \\
178\end{array}$ & 0.64 & 0.53 & 0.55 & 0.61 & 0.56 & 0.68 & 0.56 & 0.66 & 0.70 & 0.58 & 0.66 & 0.75 & 1.00 & & & & & & & \\
\hline $\begin{array}{l}\text { DRGR-32- } \\
100\end{array}$ & 0.63 & 0.54 & 0.51 & 0.53 & 0.50 & 0.61 & 0.60 & 0.53 & 0.64 & 0.54 & 0.63 & 0.71 & 0.76 & 1.00 & & & & & & \\
\hline $\begin{array}{l}\text { DRGR- } \\
308\end{array}$ & 0.70 & 0.56 & 0.56 & 0.55 & 0.60 & 0.59 & 0.58 & 0.63 & 0.61 & 0.59 & 0.65 & 0.69 & 0.76 & 0.78 & 1.00 & & & & & \\
\hline DC 95-118 & 0.58 & 0.61 & 0.64 & 0.63 & 0.68 & 0.61 & 0.58 & 0.55 & 0.54 & 0.59 & 0.60 & 0.59 & 0.59 & 0.58 & 0.73 & 1.00 & & & & \\
\hline DC 4-11 & 0.60 & 0.59 & 0.51 & 0.63 & 0.58 & 0.66 & 0.60 & 0.63 & 0.66 & 0.56 & 0.65 & 0.71 & 0.66 & 0.65 & 0.70 & 0.73 & 1.00 & & & \\
\hline DC-58-7 & 0.58 & 0.64 & 0.54 & 0.55 & 0.58 & 0.71 & 0.53 & 0.55 & 0.61 & 0.51 & 0.55 & 0.54 & 0.64 & 0.60 & 0.55 & 0.65 & 0.63 & 1.00 & & \\
\hline DC-095-7 & 0.66 & 0.58 & 0.58 & 0.51 & 0.59 & 0.65 & 0.61 & 0.54 & 0.53 & 0.50 & 0.59 & 0.55 & 0.58 & 0.56 & 0.56 & 0.61 & 0.59 & 0.74 & 1.00 & \\
\hline DC-ANJ & 0.65 & 0.61 & 0.61 & 0.58 & 0.60 & 0.69 & 0.58 & 0.55 & 0.56 & 0.54 & 0.63 & 0.56 & 0.59 & 0.63 & 0.63 & 0.63 & 0.63 & 0.73 & 0.91 & 1.00 \\
\hline
\end{tabular}


Int.J.Curr.Microbiol.App.Sci (2018) 7(3): 426-434

Fig.1 DNA amplification pattern of 20 genotypes of cotton
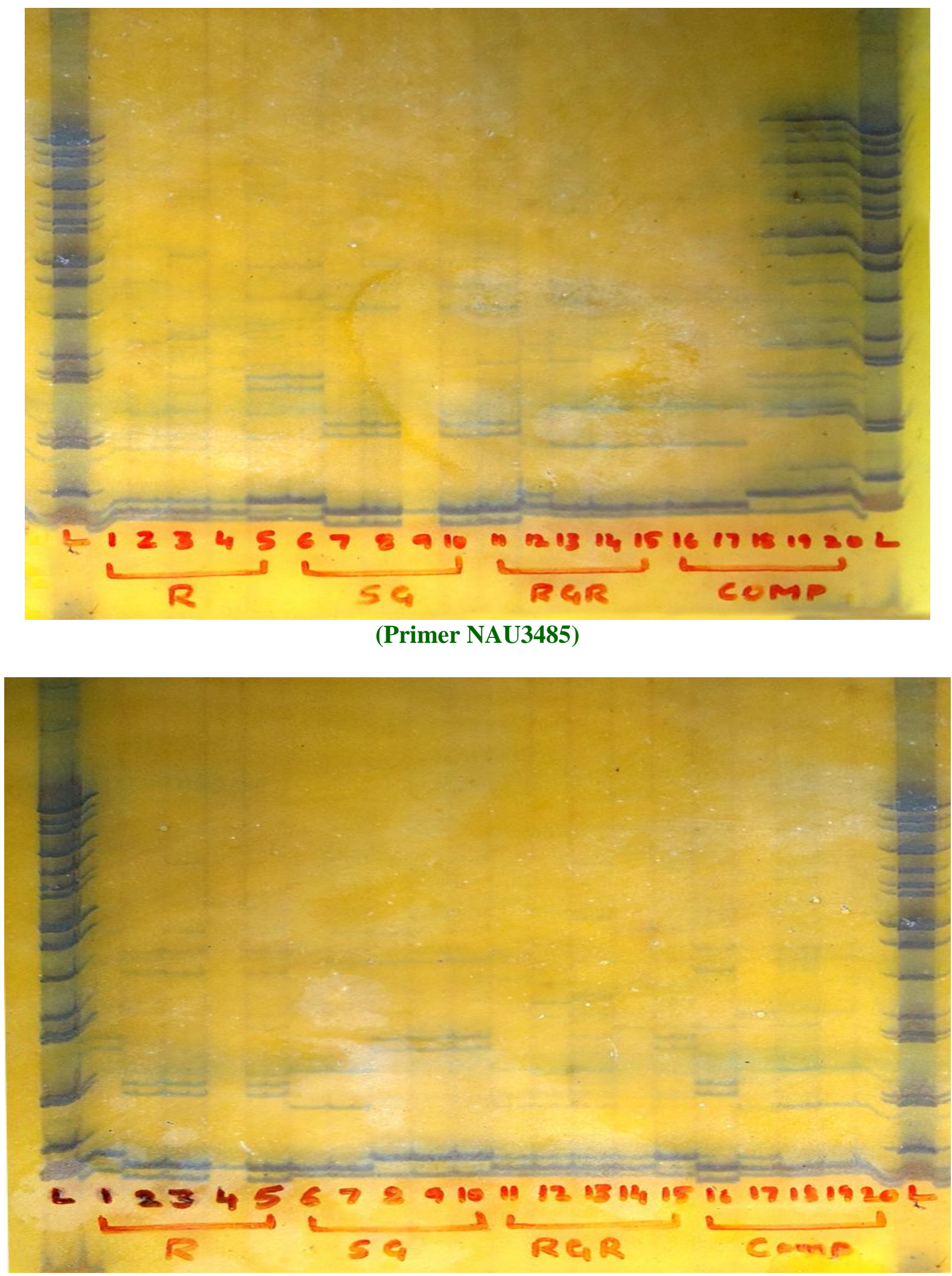

(Primer JESPR58) 
Fig.2 Dendrogram obtained from pooled data of SSR profiles of cotton genotypes from different heterotic groups (Gossypium hirsutum L.)

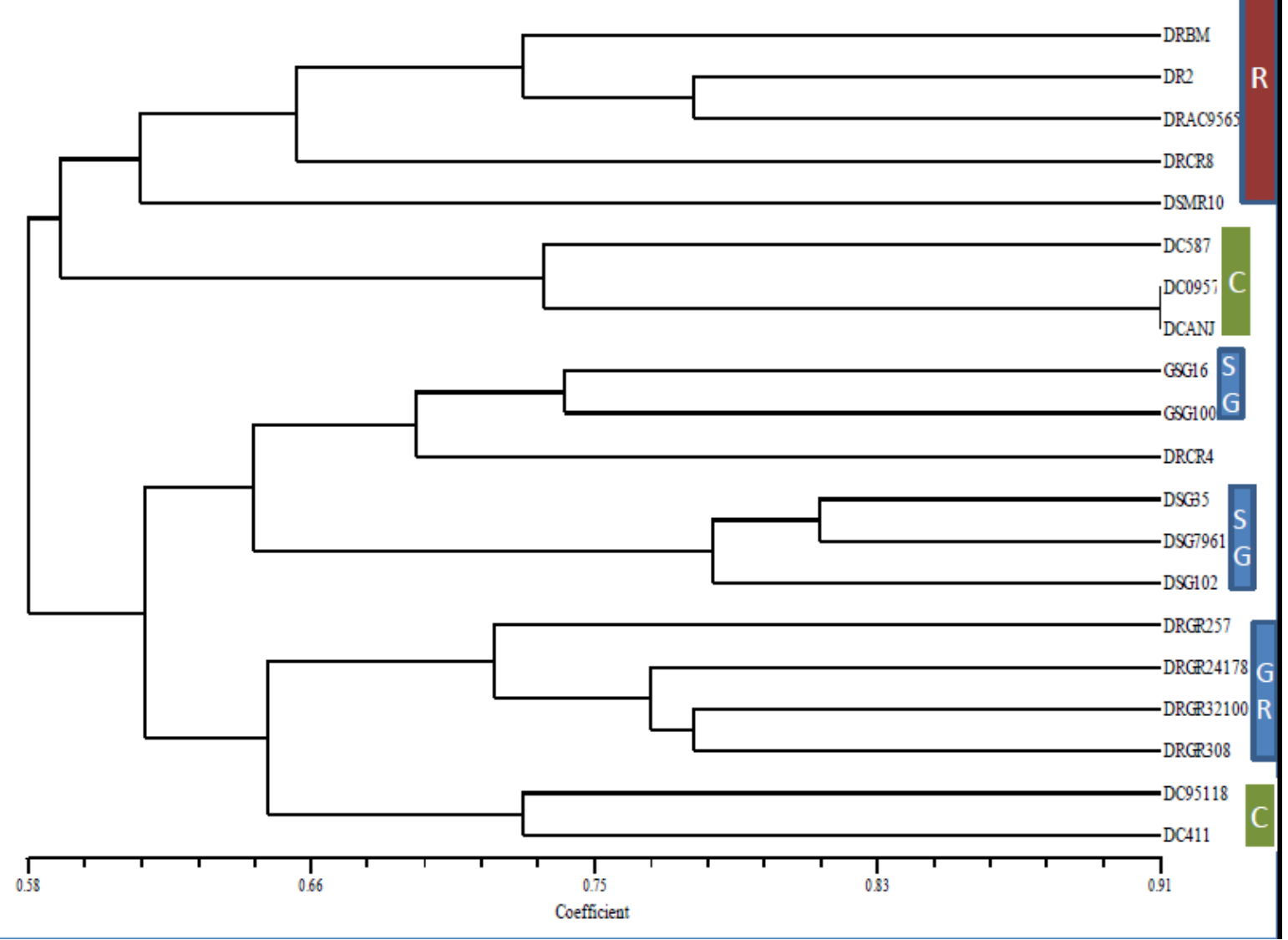

The dendrogram constructed from the pooled data (Fig. 2) revealed five distinct clusters at 0.70 per cent similarity. Cluster I had three genotypes (DBM, DRC-9565 and DR2), Cluster II included three genotypes (DC-5-87, dc-0957 and DC-ANJ), cluster III consists of (DSG-16 and DSG-100), cluster IV had four RGR-genotypes (DRGR-24-178, DRGR-257, DRGR-32-100 and DRGR-308) while, cluster $\mathrm{V}$ consists of two compact genotypes viz., DC-95-118 and DC-4-11. In generally higher similarity was observed among the elite lines of each heterotic groups and less similarity was noticed between the elite lines of heterotic groups but in most of the elite lines low range of distance was detected between the elite lines of each heterotic group which might be the refection of less number of markers used in the present study. Hence it is a worthwhile investigation to use highly saturated map of markers particularly linked to QTLs affecting most of the traits, to assess diversity and to predict the level of heterosis between the genotypes at the level of different genomic points.

\section{References}

Saghai-Maroof, M. A., Soliman, K. M., Jorgensen, R. A. and Allard, R. W., 1984, Ribosomal DNA spacer length polymorphism in barley: Mendelian inheritance, chromosomal location and population dynamics. Proc Natl Acad Sci, USA, 81: 8014-8018.

Smith, O. S., Smith, J. S. C., Bowen, S. L., Tenborg, R. A. and Wall, S. J., 1990, Similarities among a group of elite 
maize inbreeds as measured by pedigree, $\mathrm{F}_{1}$ grain yield, grain yield, heterosis and RFLPs. Theor. Appl. Genet., 80: 833-840.

Tatineni, V., Cantrell, R. G. and Davis, D. D., 1996, Genetic diversity in elite cotton germplasm determined by morphological characteristics and RAPDs. Crop Sci., 36: 186-192.
Zhang Q., Saghai M.A., Yang G.P., Liu K.D., Zhou Z.Q., Gravois K.A., C.G. Xu, and Gao Y.G., 1995, Correlations between molecular marker polymorphism and hybrid performance in rice, Plant Genome IV Conference, San Diego, CA, pp.307.

\section{How to cite this article:}

Kencharaddi, H.G., R.R. Hanchinal, S.S. Patil, S.M. Manjula, Ravi Kulkarni, C.V. Usharani and Soregoan, C.D. 2018. Molecular Characterization of Heterotic Groups of Cotton through SSR Markers. Int.J.Curr.Microbiol.App.Sci. 7(03): 426-434.

doi: https://doi.org/10.20546/ijcmas.2018.703.050 